\title{
Binary metal-metal oxide superlattice nanostructures from their metal and metal oxide nanocrystals
}

\author{
Yong $\mathrm{Li}^{*}$
}

Supported metal catalysts such as $\mathrm{Pt}-\mathrm{Sn} / \mathrm{Al}_{2} \mathrm{O}_{3}, \mathrm{Cu} / \mathrm{ZnO} /$ $\mathrm{Al}_{2} \mathrm{O}_{3}$, and $\mathrm{Pt}-\mathrm{Rh} / \mathrm{CeO}_{2}-\mathrm{Al}_{2} \mathrm{O}_{3}$ have been industrially applied for petrochemical and environmental related reactions. The common feature of these supported catalysts is that 1 to $10 \mathrm{~nm}$ metal nanoparticles are highly dispersed on high surface area porous oxides. The microstructure of the catalyst on the nanoscale in terms of size, morphology, and interface strongly influences the dispersion and chemical states of the metal nanoparticles, which in turn determines the chemical environment of the active sites, and the activation energy and reaction pathway [1]. However, supported metal catalysts are conventionally prepared by aqueous phase impregnation, coprecipitation, and deposition-precipitation, which give structurally non-uniform catalysts with wide size distribution of metal particles, random spatial location of the metal particles and disordered interface. These complicated microstructures either lower the efficiency of the catalysts or limit the establishing of a structure-performance relationship, which is fundamental data in heterogeneous catalysis. For example, 2 to $5 \mathrm{~nm}$ Au nanoparticles dispersed on reducible oxides are highly active for CO oxidation at low temperatures. Several hypotheses including the existence of Au cations, Au clusters, Au nanoparticles, and $\mathrm{Au}$-oxide perimeter interfaces have been proposed as the catalytically active sites and to explain the size dependence relationship [2], but a conclusion is still lacking to date.

The rapid development in self-assembly on the nanoscale using morphology- and size-controlled metal and metal oxide nanocrystals as building blocks now offers the feasibility to fabricate binary superlattices that integrate the chemical and physical properties of each component in synergistic interactions in the periodic architecture [3,4]. The exactly controlled size of the building blocks eliminates the problem of the wide size distributions of metal and oxide particles, which would allow the clarification of the size dependence relationship. More importantly, the highly uniform nanostructures and accurately controlled stoichiometry of the building blocks gave well-defined surface arrangements, interfacial nanostructures, and spatial locations. Because the interface between the metal and oxide nanocrystals in the designed catalyst structure is fixed, the amounts at the desired interface can be easily counted from the long range ordered structure. Therefore, binary superlattices are expected to be potential model catalysts for bridging the materials gap between model catalysts and practical catalysts.

Murray and his colleagues have assembled semiconductor (PdSe, $\mathrm{PbS}, \mathrm{Fe}_{2} \mathrm{O}_{3}$ ) and metal ( $\mathrm{Pd}, \mathrm{Au}, \mathrm{Ag}$ ) nanoparticles into ordered nanostructures [3]. The key in this process is that the liquid-air interface acts as an effective platform to organize colloidal nanoparticles. Monodispersed metal and oxide nanoparticles were first dispersed in hexane with the aid of a suitable surfactant. Then a drop of the mixed solution was spread over the surface of diethylene glycol. After the slow evaporation of hexane, a floating film consisting of binary superlattices was obtained. Recently, they extended this liquid-air interface self-assembly technique to synthesize $\mathrm{Au}-\mathrm{FeO}_{x}$ superlattices consisted of $\mathrm{Au}$ and $\mathrm{Fe}_{3} \mathrm{O}_{4}$ nanocrystals of $6 \mathrm{~nm}$ and $16 \mathrm{~nm}$, respectively [5]. By simply adjusting the mole ratio of $\mathrm{Au}$ and $\mathrm{Fe}_{3} \mathrm{O}_{4}, \mathrm{Au}-\mathrm{FeO}_{x}$ with the crystalline structures of $\mathrm{CuAu}, \mathrm{AlB}_{2}$ and $\mathrm{NaZn}_{13}$ were obtained (Fig. 1). Since the sizes of the building blocks were fixed, the perimeter of the interface between $\mathrm{Au}$ and $\mathrm{FeO}_{x}$ was uniform and the number of $\mathrm{Au}-\mathrm{FeO}_{x}$ perimeter per $\mathrm{Au}$ was counted to be 4,3 and 1.85. The $\mathrm{Au}$ and $\mathrm{Fe}_{3} \mathrm{O}_{4}$ nanocrystals exhibited negligible $\mathrm{CO}$ oxidation, while the $\mathrm{Au}-\mathrm{FeO}_{x}$ superlattices were active and the rate of $\mathrm{CO}$ oxidation increased linearly with the number of $\mathrm{Au}-\mathrm{FeO}_{x}$ interfaces. This linear relationship identified that the active site for $\mathrm{CO}$ oxidation is the $\mathrm{Au}-\mathrm{FeO}_{x}$ interfaces. These results are interesting and instructive for creating novel catalysts and to explore the active sites of CO oxidation on gold nanocatalysts. However, the overall activity of the superlattices for CO oxidation normalized to the weight of $\mathrm{Au}$ was lower. The reaction rate over $\mathrm{Au}-\mathrm{FeO}_{x}$ superlattices with the structures of $\mathrm{CuAu}$ at $150{ }^{\circ} \mathrm{C}$ was $1.6 \times 10^{-6} \mathrm{~mol} \mathrm{~s}^{-1} \mathrm{~g}^{-1} \mathrm{Au}$. In a previous work reported by Xu et al. [6], $\mathrm{Au} / \mathrm{ZrO}_{2}$ nanocomposites composed of $5.4 \mathrm{~nm} \mathrm{Au}$ and 5-10 $\mathrm{nm} \mathrm{ZrO}_{2}$ nanoparticles gave a $\mathrm{CO}$ oxidation rate as high as $93.5 \times 10^{-6} \mathrm{~mol} \mathrm{~s}^{-1} \mathrm{~g}^{-1} \mathrm{Au}$ at $70^{\circ} \mathrm{C}$. The $\mathrm{Au}-\mathrm{ZrO}_{2}$ boundaries were proposed to be the active sites. As the size of the gold particles were similar ( $6.0 \mathrm{~nm}$ vs $5.4 \mathrm{~nm}$ ) in these two systems, the much 


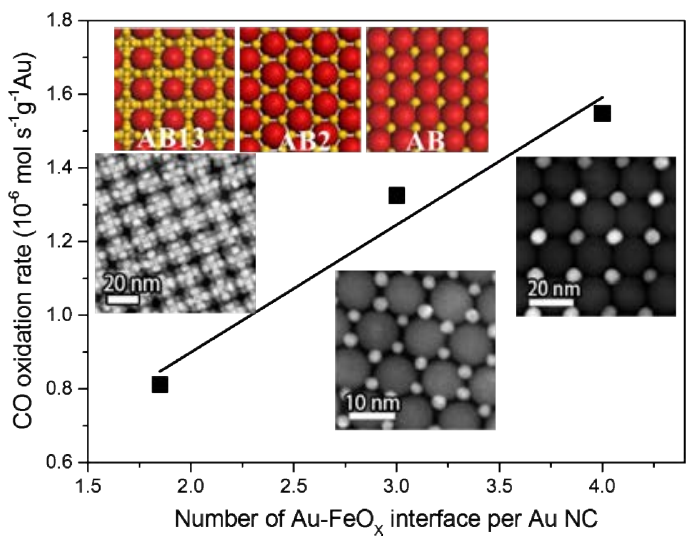

Fig. 1. The relationship between CO oxidation rate and number of $\mathrm{Au}-\mathrm{FeO}_{x}$ interfaces per Au nanocrystal. Reproduced with permission from Ref. [5], Copyright 2013, American Chemical Society.

higher reaction rate on the $\mathrm{Au} / \mathrm{ZrO}_{2}$ sample may indicate that the relatively larger size of $\mathrm{FeO}_{x}(16 \mathrm{~nm})$ nanoparticles had decreased the number of $\mathrm{Au}-\mathrm{FeO}_{x}$ interfaces. It is likely that decreasing the particle sizes of $\mathrm{Au}$ and $\mathrm{FeO}_{x}$ would maximize the number of active sites and enhance the catalytic activity for CO oxidation.

In addition, binary superlattices also have significantly enhanced stability towards thermal sintering. $\mathrm{Au}-\mathrm{FeO}_{x}$ with the $\mathrm{AlB}_{2}$ structure retained the long range ordered structure after a thermal treatment at $200{ }^{\circ} \mathrm{C}$ in a $\mathrm{N}_{2}$ atmosphere. For comparison, $\mathrm{Au}-\mathrm{FeO}_{x}$ prepared by the random mixing of $6 \mathrm{~nm} \mathrm{Au}$ and $16 \mathrm{~nm} \mathrm{Fe}_{3} \mathrm{O}_{4}$ was severely sintered because of its disordered structure. Further increasing the temperature to $400{ }^{\circ} \mathrm{C}$, $\mathrm{Au}-\mathrm{FeO}_{x}$ superlattice in the monolayer state largely kept the original nanostructure. Evidently, the binary superlattices improved the thermal stability of the supported metal catalysts because the ordered arrangement of oxides nanoparticles in the binary superlattices can isolate the metal nanoparticles and inhibit their diffusion and coalescence.

Another merit of binary superlattices is the enhancement of the selectivity towards the target reaction. Yang and his colleagues assembled a nanocrystal bilayer structure composed of $\mathrm{Pt}$ and $\mathrm{CeO}_{2}$ nanocubes monolayers of $10 \mathrm{~nm}$ on a $\mathrm{SiO}_{2}$ substrate [7]. The $\mathrm{CeO}_{2}$-Pt and $\mathrm{Pt}-\mathrm{SiO}_{2}$ metal-oxide interfaces effectively catalyzed the production of propanal from the tandem reaction of methanol and ethylene, in which the former catalyzed methanol decomposition to $\mathrm{CO}$ and $\mathrm{H}_{2}$, and the latter catalyzed ethylene hydroformylation with a propanal selectivity as high as $94 \%$. In contrast, physically mixed $\mathrm{Pt}-\mathrm{CeO}_{2}-\mathrm{SiO}_{2}$ catalysts exhibited no catalytic activity for the tandem reaction, further demonstrating the unique role of the sequential metal-oxide interfaces that favored the diffusion of $\mathrm{CO}$ under the reaction conditions.

In summary, the fabrication of binary superlattices with novel metal-metal oxide structures not only gives efficient catalysts for target reactions, but also gives better understanding of the strong metal support interaction effect and would allow the establishing of structure-performance relationships. Nevertheless, some problems still remain in the preparation and potential application. First, the interaction mechanism of surfactant with the monodispersed nanoparticles and the assembly pathway of superlattices with the desired structure is still not known. Although significant progress have been made in the synthesis of metal and metal oxide nanocrystals with the requisite size and morphology in the presence of organic surfactants to stabilize the surface $[4,8]$, the optimization of reaction conditions, especially the selection of surfactants, is still empirical and the formation pathway is not always understood. This would surely influence their mutual interaction and subsequent self-assembly to superlattices. Meanwhile, the effective removal of the surfactant under mild conditions while maintaining the nanostructure is also highly desired. The other concern is the morphology effect of the superlattices. To date, the building blocks for metal-oxide systems are typically spherical nanoparticles, and less progress have been made with anisotropic morphologies with the preferential exposure of reactive facets. Morphology changes in the metal and metal oxides nanoparticles may alter the spatial arrangement of the superlattices, e.g., the selective deposition of metal nanoparticles on the facets of oxides, and the type and degree of metal-oxide interactions would affect catalytic behavior due to the well-known electronic and geometric effects.

Yong Li

Dalian Institute of Chemical Physics,

Chinese Academy of Sciences

Tel: +86-411-84379189

Fax: +86-411-84694447

E-mail: yongli@dicp.ac.cn

Received: 12 June 2014

Published: 20 July 2014

DOI: 10.1016/S1872-2067(14)60144-3

\section{References}

[1] Bell A T. Science, 2003, 299: 1688

[2] Haruta M. Angew Chem Int Ed, 2014, 53: 52

[3] Shevchenko E V, Talapin D V, Kotov N A, O’Brien S, Murray C B. Nature, 2006, 439: 55

[4] Zhang S Y, Regulacio M D, Han M Y. Chem Soc Rev, 2014, 43: 2301

[5] Kang Y J, Ye X C, Chen J, Qi L, Diaz R E, Doan-Nguyen V, Xing G Z, Kagan C R, Li J, Gorte R J, Stach E A, Murray C B. J Am Chem Soc, 2013, 135: 1499

[6] Zhang X, Wang H, Xu B Q. J Phys Chem B, 2005, 109: 9678

[7] Yamada Y, Tsung C K, Huang W Y, Huo Z Y, Habas S E, Soejima T, Aliaga C E, Somorjai G A, Yang P D. Nature Chem, 2011, 3: 372

[8] Li Y, Shen W. Chem Soc Rev, 2014, 43: 1543 